\title{
Economical Estimation of Investment for Combined Solar-Wind-Biogas Energy Plant
}

\author{
Ulviyya Mammadova
}

Department of Soils Ecology and Bonitation, Institute of Soilscience and Agrochemistry of ANAS, M.Arif 5, AZ1073, Baki, Azerbaijan

\begin{abstract}
The projecting economical advantages of combined solar-wind-biogas energy plant (CSWBEP) was firstly estimated in the paper. For the very plant's expedient usage instead of fire-wood from forests in mountainous and foothill regions has been taken into consideration. For this purpose the Discount method which is utilized in the current market economy was applied. Discount coefficient is used for economical estimation of investment projects is considered in realization of calculating effectiveness of the plant. By the method economical beneficence of the project was determined in which building and exploitation of CSWBEP during 20 years has been spoken. Taking into account Discount coefficient on the years the project was estimated and economical index of the factors proving project effectiveness was revealed at the result of calculations.
\end{abstract}

Keywords Discount Coefficient, Economical Estimation, Energy Effective

\section{Introduction}

For woodlands protection and forest soils safety as the alternative of forest wood on mountainous and foothill zones CSWBEP was presented. In CSWBEP solar, wind and biogas energy sources are together utilized in individual houses in the region. Further project's economical valuation for the investigation area where application of CSWBEP is intended is one of the major conditions. That's why during the investigating income and outcome are taken into consideration in comparison with exploitation duration. Payback period of the investment should be known beforehand for determining the further state of the project on the base of these results. In this case besides capital within the investment, coming money index[11] (unit) ought to be calculated in advance and these economical indexes have to be estimated from effectiveness[6] point of view. Because while preparing the business plan of the project economical efficiency in difference with others can prove perspectivity and possibility of project realization[7].

During organizing the presented CSWBEP's ecological clean energy project, investor's interest who will lead to the project, environmental safety degree (prevention of forest hewing processes), provision of energy demand (for heating and hot water supply) for the villages settled around the Nature preserve have been considered. Total sum of the presented project is 1000000 AZN. I should say that such

* Corresponding author:

uf_samadova@yahoo.com (Ulviyya Mammadova)

Published online at http://journal.sapub.org/economics

Copyright @ 2012 Scientific \& Academic Publishing. All Rights Reserved kind of projects are implemented by the government or sometimes by the private companies who have won in the tender. It doesn't matter, generally the project has great economical, ecological and energy advantages[8]. Thus realization of the project possesses several facets. In one hand the very project can reduce additional and obligatory expenditures from the government budget which are spent for energy (gasing), afforestation, forestation and solving ecological problems formed after pollutions. In other hand the project can supply energy need of the local population whose social-economical state is under bad condition and at the same time it gives guarantee to safety life (prevention of gas explosion, poisoning from black coal burn-off).

So the given ecological clean energy project based on CSWBEP is firstly economy of the forest wood and provision of woodlands protection. Additionally this may decrease amount of fossil fuels (organic biological fuels) utilization that leading to the emissions[4] in the environment, especially in atmosphere. Whilst estimating investment projects economical effectiveness and selecting them the following indexes[1]:

I. Pure discount income or integral benefit ( $P D P$ );

II. Internal profit norm or internal benefit norm ( IPN );

III. Profit index or payability index ( PI );

The above mentioned economical rationality rates are defined during calculation of the clean energy project based on CSWBEP.

\section{Research Method and Object}

In order to prevent the forest wood's from being hewed by the local population living surrounding villages solar, wind 
and biomass energy potentials utilization was presented. By this purpose energetically profitable CSWBEP's building project has been planned. In the regions where woodlands spread for provision of the energy demand the project has exceptional relevance. The work can be accepted as the advisable investment project for reducing coming economical expenditures, for solving further ecological damages and for supplying necessary energy demand of the mountains settlements, villages surrounding woodlands. In the forests protection measurements on mountainous and foothill belts economical beneficence of CSWBEP exploitation has to be determined before realizing the project [9]. Thus economical appreciation methods are to be used which are well-known and utilized largely in the international practice. So future expenses for object building, exploitation and incoming capital from the intended project should be defined and compared with each-other depending on the time factor. The capital means being spent to the investment project realization and the beneficial income from the project are brought to the same time and evaluated.

When money means flow cost is previously appraised depending on the time discount coefficient is used[2]. For determining indexes of discount coefficient bank rate norms and other factors can be taken into consideration. Discount coefficient $\left(D_{c}\right)$ is calculated due to the following formula:

$$
D_{c}=1+(1+r)^{n}
$$

Here $r$-discount norm; $n$ - discount periods, year.

In investment project realization results can be expressed into money by $P D P$ indexes. While carrying out the investment project $P D P$ is determined in the comparison between current incoming money means ( ICM ) and investment means cost (IMC) spent to the very project realization:

$$
P D P=I C M-I M C
$$

Here $P D P$ - discount cost of the current incoming money during the realization of the investment project; $I M C$ - investment means cost spent fro the realization of the investment projects (money sum).

During estimating investment project if $P D P$ gets negative mark or equals to zero, then the very project realization won't bring additional income to the investor[10]. IPN internal profit norm or internal benefit norm index characterizes beneficial level of investment project realization.

Income index is based on the discount norm. it is expressed by the irrelativeness between future discounted pure coast of the earned money flow from the capital investment and the current cost of the money spent for the project realization [7].

$$
I P N=\frac{P D P}{I C} 100
$$

$I P N$ - internal profit norm, $P D P$ - pure discount profit and $I C$ - investment capital.

Mark of IPN should be taken in equal to discount norm. In discounting process pure discount profit will be equal to zero.
Profit index PI is determined by the relation between money means discounted cost gained at the result of project realization and investment cost.

$$
P I=\frac{C M U}{I C}=2,55 \text { times }
$$

$P I$-profit index, CMU - current discounted cost of the coming money unit while realizing the investment project and IC is the investment cost being spent to the project realization.

If $\boldsymbol{P D P}$ gets positive mark, then it will be $\boldsymbol{P I}>1$. whether $\boldsymbol{P I}$ gets mark less than unit or equals to unit, then the project isn't, because this project won't bring additional profit to investor. $\boldsymbol{P b P}$ factor is the wide used parameter in economical assessment of the investment projects. $P b P$ expresses pay-back possibility of expenses spent to investment project realization within minimal duration. In other word $\mathbf{P b P}$ is the factor which reflects time of the additional profit after investment completion to the project. $P b P$ is calculated by the following:

$$
P b P=\frac{I C}{C M U(t)}
$$

$P b P$ - payback period, IC is the investment cost and $C M U(t)$ is coming money unit depending on the time.

How longer $P b P$ is investment project realization process has greater riskiness rate. In marketing condition this factor is to be taken into considration for implementing investment project.

\section{Result and Discussion}

Above mentioned economical effectiveness appreciation methods of investment project and indexes gives opportunity to determine efficiency of the project beforehand.

Building and exploitation of the presented CSWBEP on these methods are intended for the regions where massively forest cutting processes are carried out. That's why it is necessary to determine efficiency rate of this investment project for saving ancient woodland areals on the high and middle mountainous belts[12]. By this purpose estimating and calculating economical benefits of presented investment project on CSWBEP's building and exploitation should be done. For the calculation the following initial information have to be looked through:

(a) The investment volume to the CSWBEP project is 1000000 AZN;

(b) The exploitation duration of the investment project

(c) Money means being economized for a year is 3006000 AZN at the result of project realization, so the total money sum for 20 year can be determined:

$20 \times 3006000=60120000$ AZN.

Depending on the time in estimation of money means flow cost the used discount norm consists of $10 \%$.

In the initial information mentioned above, exploitation duration of the project was taken in equal to plant's amortization duration. It stands the exploitation of the plant will be 
continued.

But in the calculations the very duration hasn't taken into consideration. On the years the results have been given at the following table 1 .

For building and exploitation of CSWBEP economical calculation is carried out by using tables indexes obtained due to the four methods and calculations. In the first, by using the initial information and the table indexes CSWBEP project's pure discount profit will be:

$$
P D P=P-I C=1558551 \mathrm{AZN}
$$

So, in the presented investment project the obtained pure discounted profit is consists of 847034 AZN. It is that on the mountainous and foothill regions where woodland areas widely extended if this project (in the cost of 1000000 AZN) is realized after 20 years both the spent sum to the project will be paid back and the additional 1558551 AZN profit will be obtained.

By using the second method and the indexes at the table on CSWBEP project IPN - internal profit norm is determined. In this case so discount norm should be revealed that while using it current cost of the money means flow obtained within 20 years can be equalled to the investment coast spent to the project. The searched discounted norm can be found as the follows:

$$
I P N=\frac{P D P}{I C} 100=15,58 \%
$$

Thus, the project internal profit norm is high.

By using the third method and the indexes at the table investment project profit index is calculated as:

$$
P I=\frac{C M U}{I C}=2,55 \text { times }
$$

Profit index mark is greater than unit, so investment project realization is considered economical beneficent. Thus the spent money to the project can prove itself 2,55 times.

By using the fourth method and the indexes at the table spent money for the project implementation pay-back can be calculated:

$$
C M U(t)=\frac{\sum_{t=1}^{n} C M U^{n}}{I C}=255855,1 \mathrm{AZN}
$$

The pay-back duration of the investment is determined as follows:

$$
P b P=\frac{I C}{C M U(t)}=3,9 \text { year }
$$

So investment resources spent to CSWBEP's building and exploitation will be paid back during 3,9 years. According to the indexes calculated above, I should notice that the presented investment project actualization is possible. On the mountainous and foothill regions where there are woodlands in order to prevent the forest wood from being hewed for supplying energy demand this project has great importance. Due to the current state and condition the project is advisable from economical and ecological points of view. So, economy of fossil fuels can reduce amount of the hazardous gases to the atmosphere [7].

Table 1. The result of the calculation

\begin{tabular}{|c|c|c|c|c|}
\hline years & $C M U$ & $D_{\text {coefficient }}$ & $C M U(t)=C M U(t) D_{\text {coefficient }}$ & $D_{\text {coefficient }}$ \\
\hline I & 300600 & 0,909 & 273274 & 0,909 \\
\hline II & 300600 & 0,826 & 248416 & 0,826 \\
\hline III & 300600 & 0,751 & 225840 & 0,751 \\
\hline IV & 300600 & 0,683 & 205310 & 0,683 \\
\hline V & 300600 & 0,620 & 186642 & 0,620 \\
\hline VI & 300600 & 0,546 & 169688 & 0,546 \\
\hline VII & 300600 & 0,513 & 154268 & 0,513 \\
\hline VIII & 300600 & 0,466 & 140230 & 0,466 \\
\hline IX & 300600 & 0,424 & 127484 & 0,424 \\
\hline X & 300600 & 0,385 & 115882 & 0,385 \\
\hline XI & 300600 & 0,350 & 105210 & 0,350 \\
\hline XII & 300600 & 0,318 & 95590 & 0,318 \\
\hline XIII & 300600 & 0,289 & 86872 & 0,289 \\
\hline XIV & 300600 & 0,263 & 79058 & 0,263 \\
\hline XV & 300600 & 0,239 & 71844 & 0,239 \\
\hline XVI & 300600 & 0,217 & 65230 & 0,217 \\
\hline XVII & 300600 & 0,198 & 59518 & 0,198 \\
\hline XVIII & 300600 & 0,180 & 54108 & 0,180 \\
\hline XIX & 300600 & 0,164 & 49298 & 0,164 \\
\hline XX & 300600 & 0,149 & 44789 & 0,149 \\
\hline
\end{tabular}


Ecological efficiency estimation of the works in the direction of solving ecological problems and energy demand provision needs researches on a large scale. Because such kind of investigations fulfilment is very actual question today. Especially ecological clean energy alternative energy sources potentials' determination and new energy projects preparation within these potentials are too important. Economical evaluation of the demanded investment sum and the pure profit being gained from that project is defined due to the international practice within today's interests. In the Republic the first project cost in the field of building and exploitation of renewable energy plants was 500000 AZN. That investment project concerned to the solar energy plant (SEP) application in oil industry as the aiding energy source [5]. In the investment project SEP' building and exploitation for crude oil treatment in oil-well condition has been considered. The incoming profit from the investment spent to the project, pay-back duration of the capital given to the project and other economical advantageous factors were calculated and the fulfilment of the project was validated [3]. In the very project only the plant working with solar energy parabolic and parabolic trough SEPs' application was intended. That's why the economical conveniences of these energy plants were given. The investment project presented which sum is 1000000 AZN concerns to the application of solar, wind and biomass energy potentials in combined condition. Such project has sum precedence and energy sources in comparison with the first one. Also the project completion has been intended in the villages surrounding Pirgulu State Nature Preserve that protected by the government. The territory is suitable for realizing the pilot project.

\section{Conclusions}

Building and exploitation of the presented CSWBEP has been considered in the investigation region Pirgulu. After having calculated economical effectiveness of the investment project with 1000000 AZN sum I've come into the following conclusions:

- Difference between current cost of the incoming money means investment means cost spent to the project realization, PDP - 1558551 AZN;

- Relation between further discounted pure cost of the money flow gained from the capital investment and current cost of the money spent to the project, IPN $-15,58 \%$;

- Relation between the discounted sum of the money means obtained at the result of the CSWBEP project implementation and investment means, $\boldsymbol{P I}$ proves itself 2,55 times;

- Depending on the exploitation the total sum of the incoming money means $C M U(t)=255855,1$ AZN;

- Pay-back duration of the expenses spent to the CSWBEP, $P b P-3,9$ years.

As the conclusion of the economical estimation, I should notice that the presented investment project on CSWBEP's application with 1000000 AZN sum is so significant from economical, ecological and energy point of view for protecting the environment. Not only in Pirgulu region but also in any mountainous and foothill regions this project can be realized. For energy demand provision and forest wood economy the project was sufficiently validated. This gives opportunity to decide the investment to the project.

\section{ACKNOWLEDGMENTS}

All these investigations were realized within my doctoral dissertation based on the State Programs on «Reforestation and Forest Extension» signed on 2003, February 18 and «Application of Alternative and Renewable Energy Sources in Azerbaijan Republic» signed on 2004, October 21.

\section{REFERENCES}

[1] B.A. Ahmadov. Development Problems of Azerbaijan Oil Refining Industry. Baki, «Elm», 2003, 342 p.

[2] B.M. Krivonogov. Improving the Effectiveness of Gas Firing and Environmental Safety. L: Nedra, 1986, 280 p.

[3] F.F. Mammadov., Y.A. Malikov. Economical Aspects of Solar Energy Application in oil Industry. Azerbaijan Oil Industry Journal, № 8, 2006, p.p. 47-51.

[4] F.F. Mammadov., Y.A. Malikov. Effectiveness of Solar Energy Application in Crude Oil Dehydration Process. Azerbaijan Oil Industry Journal, № 1, 2006, p.p. 54-59.

[5] F.F.Mammadov, U.F.Samadova. Perspectives of Wind Energy Application in Azerbaijan. International Scientific Journal «Alternative Energy and Ecology», № 7 (75) 2009, p.p. 52-64.

[6] M.M.Mammadov,Y.A.Maliкоv, A.M.Ahmadli. Business Plan on Investment Projects. Baki: «Elm», 2000, 165 p.

[7] Malikov Ya.A., Mammadov F.F. Economical aspects of renewable energy application in industry. TPE-2006, Turkey.

[8] U.F. Samadova. Solar and Wind Energy Application for the Woods and Forest Soil's Protection // Renewable Energy Congress X, Glasgow, Scotland, 19-25 July, 2008, p.p 2278-2280.

[9] U.F.Samadova. Effective Protection of Forest Soils in Azerbaijan, International Journal of Academic Research, № 1, vol. 1, 2009, pp. 53-58.

[10] U.F.Samadova. Importance of Solar Energy for the Environment. Municipality and Ecology, existing problems and their possible solution ways, Materials of Scientific Practical Conference. Baki, 2006, pp. 132-135.

[11] U.F.Samadova. Open Evaluation Scale Woodland and Woodless soils (Shamakhi), Ecology and Water Industry (Scientific-Technical and Production) Journal. № 4, 2009, pp. 30-34.

[12] V.V.Shermet, V.M.Pavlyuchenko, V.D.Shapiro and others. Investment Operation. M.: «Vishaya shkola», 1998. 512 c. 